\title{
Conservative treatment with methotrexate of ectopic pregnancy
}

\begin{abstract}
As a life-threatening condition, ectopic pregnancy has gained a lot of concerned by physicians. To avoid unnecessary surgical treatment, conservative medical treatment with methotrexate has been used intensively. Although other alternative conservative treatments are available, methotrexate is still popular due to its convenience, safety and effectiveness. This mini review covers general idea of methotrexate as a conservative medical treatment for ectopic pregnancy.
\end{abstract}

Keywords: methotrexate, ectopic pregnancy, beta-HCG
Volume 3 Issue 3 - 2017

\author{
Randy Polyanna PO, ${ }^{1,2}$ Aixingzi Aili, \\ 'School of Medicine, Tongji University, China \\ ${ }^{2}$ Department of Gynecology, Shanghai First Maternity and Infant \\ Health Hospital affiliated to Tongji University, China
}

Correspondence: Aixingzi Aili, Department of Gynecology, Shanghai First Maternity and Infant Health Hospital affiliated to Tongii University, Shanghai 200I26, China,

Email1819483078@qq.com

Received: June 08, 2017 | Published: December 08, 2017
Abbreviations: MTX, methotrexate; EP, ectopic pregnancy; beta-hCG, beta human chorionic gonadotropin; DNA, deoxyribonucleic acid; RNA, ribonucleic acid; IVF, In Vitro fertilization; FSH, follicle stimulating hormone; $\mathrm{LH}$, luteinizing hormone

\section{Introduction}

Ectopic pregnancy is an important cause of mortality in women in reproductive age. It is a life threatening condition and if not diagnosed and treated carefully, it could affect the mother's future ability to reproduce. The rate of ectopic or extra uterine pregnancy is $1.3-2 \% .{ }^{1}$

Diagnosis of ectopic pregnancy is vital, as it could save the mother's life before uterine rupture occur. Uterine rupture accounts $6 \%$ of pregnancy related deaths and the leading cause of first trimester maternal death. ${ }^{2}$ Diagnosis can be done by holistic approach from patient's history, physical examination and radiology and laboratory results. The most common complaint for patients to seek for medical attention is lower abdominal pain. Physicians should consider an early beta-hCG testing immediately followed by trans-vaginal ultrasound following a positive beta-HCG results. ${ }^{3}$

Systematic methotrexate (MTX) is a commonly used conservative first-line treatment for patients with ectopic pregnancy.Other conservative treatment includes laparoscopy, uterine artery embolism or dilation and curettage (D\&C) with Foley's balloon tamponade. ${ }^{4}$ Medical treatment remains as a choice for physicians, and greater number of patients treated medically than surgically. Despite conservative treatment being the first line choice for ectopic pregnancy, it is still not a common practice in developing countries. ${ }^{5}$ In this review, we summarize the effectiveness of methotrexate in the treatment of ectopic pregnancy.

\section{Dosing and usage}

Methotrexate is a folate antagonist, the role is to halt the cycle process of DNA and RNA reproduction by folic acid. At different concentration level of MTX, different cellular phase is affected, but mostly in S phase of cell cycle. ${ }^{6}$

There are two commonly used regimens for intramuscular methotrexate, one is a multiple-dose regimen of $1 \mathrm{mg} / \mathrm{kg}$ of methotrexate every other day, alternating with $0.1 \mathrm{mg} / \mathrm{kg}$ of leucovorin rescue, for up to 4 doses, ${ }^{7}$ or a single-dose regimen based on the body surface area $(50 \mathrm{mg} / \mathrm{m} 2)$ without leucovorin rescue. ${ }^{8}$ Studies have been done to compare the two regimens and the result was that the difference between the two regimens are not statistically significant. ${ }^{9}$ But it is also stated that the side effects from the multiple-dose is higher than single-dose.

In single-dose regime, beta-hCG levels have to be repeated on day 4 and 7 , a decline by $\geq 15 \%$ of beta-hCG levels between days 4 and 7 is considered successful. If not, a second dose should be administered. A success first dose should be followed up weekly by repeat checking of beta-hCG levels. Failure of beta-hCG levels to fall by $\geq 15 \%$ on each successive week also resulted in repeat dosing of methotrexate. ${ }^{10}$

\section{Indications and contraindications}

Conservative treatment with MTX is not always successful. Complete considerations must be taken into account whether or not a patient is indicated for conservative treatment. Patients who have the following criteria are considered good candidate: hemodynamically stable, with beta-hCG $<5000 \mathrm{mIU} / \mathrm{ml}$, unruptured $<3.5 \mathrm{~cm}$ mass and no embryogenic cardiac activity. While patients with beta-hCG $>5000 \mathrm{mIU} / \mathrm{ml}$, mass $>3.5 \mathrm{~cm}$, present of embryonic cardiac activity and significant abdominal pain are considered poor candidate. ${ }^{7}$

\section{Success rate}

Many studies have showed the success cases of MTX for EP. A 5 year study from Pakistan was conducted, Systemic single-dose MTX was administered to 58 of $98(59.2 \%)$ patients with EP, and was successful in $42(72.4 \%)$ patients. Three (3\%) patients in the treatment failure group received second MTX doses and 13(13.3\%) underwent surgery. ${ }^{11}$ Another studywas done in India, the overall success rate was $60.6 \%$ of patients. Of the failure group, only $4.7 \%$ of patients experienced rupture of EP. No side effects were reported. The main predictors of failure were initial b-hCG value C $3.500 \mathrm{mIU} / \mathrm{mL}$ OR 4.11(1.646-12.248, 0.043) and EP diameter 3.73. ${ }^{12}$

Cirik et al. ${ }^{13}$ did a study on success rate of MTX in first and previous EP, the study reported that the requirements for additional doses was significantly higher in previous ectopic pregnancy. The success rate 
was $93.0 \%(320 / 344)$ for first ectopic pregnancy and $87.3 \%(48 / 55)$ for previous ectopic pregnancy. It is also stated that previous EP was not a predictor for treatment failure.

A much lower successful rate was also reported by Feras Sendy et al. ${ }^{14}$ with only $71 \%$ successful rate. Although it stated that the lack of a careful selection of patients as candidates for medical therapy and confining to a strict selection criterion might be the reasons.

\section{Prognosis of future fertility}

MTX treatment has been shown to not affect pregnancy outcomes. ${ }^{15}$ Underlying etiological factors and the type of the treatment modality might influence the reproductive outcome after ectopic pregnancy. Cumulative pregnancy rate was reported as $36-79 \%$ after medical treatment. ${ }^{16}$ A study was done in 2013 by Amir Wiser et al. ${ }^{17}$ That observed the subsequent IVF cycle after treatment of MTX. The study includes concentrations of estradiol, FSH and LH, and it shows that MTX does not affect the ovarian functions.

\section{Conclusion}

The choice of treatment for ectopic pregnancy is important, vital care to patients is very important as the risk of rupture is high and life-threatening. While methotrexate is the first-line treatment for physicians, careful assessments have to be thought carefully.

Although a lot of studies have proven methotrexate to be safe and effective for ectopic pregnancy, more studies can be done to compare the effectives of single-dose and multiple-dose regime, prognosis of successful pregnancy or comparison for new treatment choice such as high-intensity focused ultrasound or uterine artery embolism.

\section{Acknowledgements}

None.

\section{Conflict of interest}

The author declared no potential conflicts of interest with respect to the research, authorship, and/or publication of this article.

\section{References}

1. Craig LB, Khan S. Expectant management of ectopic pregnancy. Clin Obstet Gynecol. 2017;55(2):461-470.

2. Gatzke N, Johnson L. Ectopic pregnancy. Nurse Pract; 2014;39(12):42-47.

3. Mausner Geffen E, Slywotzky C, Bennett G. Pitfalls and tips in the diagnosis of ectopic pregnancy. Abdom Radiol. 2017;42(5):1-19.
4. Uludag SZ, Kutuk MS, Aygen EM, et al. Conservative management of cervical ectopic pregnancy: Single-center experience. J Obstet Gynaecol Res. 2017;(42):1-6.

5. Foumane P, Mboudou ET, Dohbit JS, et al. Article ectopic pregnancy in a sub- Saharan African setting. 2011. p. 79-81.

6. Stika CS. Methotrexate: the pharmacology behind medical treatment for ectopic pregnancy. Clin Obstet Gynecol. 2012;55(2):433-439.

7. Bachman EA, Barnhart K. Medical management of ectopic pregnancy: a comparison of regimens. Clin Obstet Gynecol. 2012;55(2):440-447.

8. Lipscomb GH, Bran D, McCord ML, et al. Analysis of three hundred fifteen ectopic pregnancies treated with single-dose methotrexate. Am J Obstet Gynecol. 1998;178(6):1354-1358.

9. Yang C, Cai J, Geng Y, et al. Multiple-dose and double-dose versus single-dose administration of methotrexate for the treatment of ectopic pregnancy: a systematic review and meta-analysis. Reprod Biomed Online. 2017;34(4):383-391.

10. Saadati N, Najafian M, Masihi S, et al. Comparison of Two Different Protocols of Methotrexate Therapy in Medical Management of Ectopic Pregnancy. Iran Red Crescent Med J. 2015;17(12):e20147.

11. Tas EE, Akcay GF, Avsar AF. Single-dose methotrexate for the treatment of ectopic pregnancy : Our experience from 2010 to 2015. Pak J Med Sci. 2017;33(1):13-17.

12. Alsammani MA, Moona N. Predictors of Success of a Single-Dose Methotrexate in the Treatment of Ectopic Pregnancy. J Obstet Gynecol India. 2016;66(4):233-238.

13. Cirik DA, Kinay T, Keskin U, et al. Success rates of single-dose methotrexate and additional dose requirements among women with first and previous ectopic pregnancies. Int J Gynecol Obstet. 2016;133(1):49-52.

14. Sendy F, AlShehri E, AlAjmi A, et al. Failure rate of single dose methotrexate in managment of ectopic pregnancy. Obstet Gynecol Int. 2015;2015:902426.

15. Ohannessian A, Loundou A, Courbiere B, et al. Ovarian responsiveness in women receiving fertility treatment after methotrexate for ectopic pregnancy: A systematic review and meta-analysis. Hum Reprod. 2014;29(9):1949-1956.

16. Demirdag E, Guler I, Abay S, et al. The impact of expectant management, systemic methotrexate and surgery on subsequent pregnancy outcomes in tubal ectopic pregnancy. Ir J Med Sci. 2016;186(2):1-6.

17. Wiser A, Gilbert A, Nahum R, et al. Effects of treatment of ectopic pregnancy with methotrexate or salpingectomy in the subsequent IVF cycle. Reprod Biomed. 2013;26(5):449-453. 